Article

\title{
Chemical Constituents from the Stems of Diospyros maritima
}

\author{
Chi-I Chang ${ }^{1}$, Chiy-Rong Chen ${ }^{2}$, Hsi-Lin Chiu ${ }^{3}$, Chao-Lin Kuo ${ }^{4, \dagger}$ and \\ Yueh-Hsiung Kuo ${ }^{3,5,6,+}, *$
}

1 Graduate Institute of Biotechnology, National Pingtung University of Science and Technology, Pingtung 912, Taiwan; E-Mail: changchii@mail.npust.edu.tw (C.-IC.)

2 Department of Biological Science and Technology, Meiho Institute of Technology, Pingtung 912, Taiwan; E-Mail: x2202@meiho.edu.tw (C.-R.C.)

3 Department of Chemistry, National Taiwan University, Taipei 106, Taiwan

4 School of Chinese Medicine Resources, China Medical University, Taichung 404, Taiwan; E-Mail: clkuo@mail.cmu.edu.tw (C.-L.K.)

5 Tsuzuki Institute for Traditional Medicine, College of Pharmacy, China Medical University, Taichung 404, Taiwan

6 Agricultural Biotechnology Research Center, Academia Sinica, Taipei 115, Taiwan

$\dagger$ These authors contributed equally to this work.

* Author to whom correspondence should be addressed; E-Mail: yhkuo@ntu.edu.tw; Tel.: + 886-2-33661671; Fax: + 886-2-23636359.

Received: 1 November 2009; in revised form: 7 December 2009 / Accepted: 14 December 2009 / Published: 15 December 2009

\begin{abstract}
A new phenolic, bis(6-hydroxy-2,3,4-trimethoxylphen-1-yl)methane (1) and a new butanedioate, butylmethyl succinate (2), along with twenty-nine known compounds including one naphthoquinone derivative, two chromanones, eight benzenoids, one lignan, one tocopherol, and sixteen triterpenoids were isolated from the stems of Diospyros maritima. epi-Isoshinanolone (3) was isolated in pure form for the first time. In addition, 5,7-dihydroxy-2-methylchomanone (4) was isolated from a natural source for the first time. Their structures were established on the basis of spectroscopic data as well as direct comparison with authentic samples.
\end{abstract}

Keywords: Diospyros maritima; Ebenaceae; bis(6-hydroxy-2,3,4-trimethoxylphen-1yl)methane; butylmethyl succinate 


\section{Introduction}

Diospyros maritima Blume (Ebenaceae), a medium-sized shrub, is widely distributed throughout Southern Asia. The genus Diospyros is well-known to produce various naphthoquinone derivatives, some of which exhibit cytotoxic, ichthyotoxic, germination inhibitory, and antifungal activities [1-4]. The stems of $D$. maritima has been used in Taiwan as a folk medicine as a traditional treatment for rheumatic disease [5]. In previous studies, many naphthoquinones and triterpenes were isolated from its bark, root, fruits, leaves, and twigs by Tezuka [6] and Higa [1,2]. More recently, we also have reported some new naphthoquinones [7,8], triterpenes, steroids [3,9-13], phenolic and aliphatic components [14] from the stems of this plant and found that some naphthoquinones showed strong antitumor activity [3]. In continuation of our work on the discovery of secondary metabolites from this plant, we have also isolated a new phenolic, bis(6-hydroxy-2,3,4-trimethoxylphen-1-yl)methane (1), and a new butanedioate, butylmethyl succinate (2), along with twenty-nine known compounds including one naphthoquinone derivative, epi-isoshinanolone (3) [15], two chromanones, 5,7dihydroxy-2-methylchromanone (4) [16] and 5-hydroxy-2-methylchromanone (5) [17], eight benzenoids, 1-(4,6-dihydroxy-2-methylphenyl)ethanone (6) [18], ethyl 2,4-dihydroxy-6-methylbenzoate (7) [19], 4-hydroxybenzaldehyde (8) [20], vanillin (9) [21], 4-hydroxy-3,5-dimethoxybenzaldehyde (10) [20], acetovanillone (11) [22], trans-coniferylaldehyde (12) [23], and (E)-3-(4acetyloxy-3,5-dimethoxyphenyl)-2-propenal (13) [24], one lignan, 4-ketopinoresinol (14) [25], one tocopherol, $\alpha$-tocopherol (15) [20], and sixteen triterpenoids: squalene (16) [20], lupeol caffeate (17)

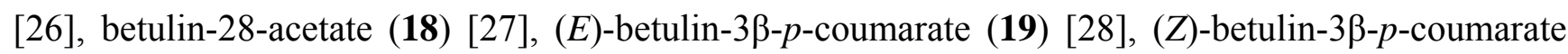
(20) [28], betulinaldehyde (21) [29], 3-oxo-20(29)-lupen-28-oic acid (22) [20], betulinic acid (23) [30], betulic acid acetate (24) [31], 3-O-betulinic acid p-coumarate (25) [32], 3-O-palmitoylerythrodiol

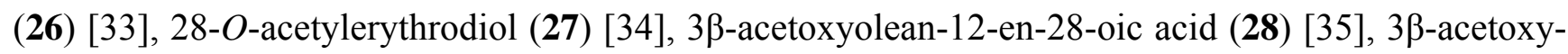

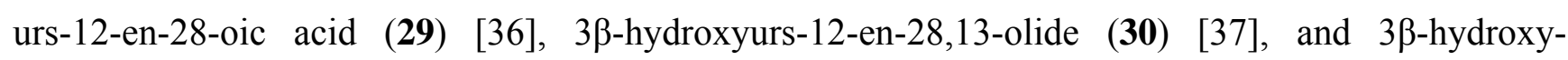
taraxastan-28, 20ß-olide (31) [38].

\section{Results and Discussion}

The EtOH extracts of the stems of D. maritima was concentrated to give a black residue which was suspended in water and partitioned successively with $n$-hexane and $n-\mathrm{BuOH}$. The combined $n-\mathrm{BuOH}$ soluble layer was subjected to repeated chromatography using silica gel and further purification by semipreparative HPLC to furnish two new compounds, bis(6-hydroxy-2,3,4-trimethoxylphen-1yl)methane (1) and butylmethyl succinate (2), in addition to twenty-nine known compounds. The identification of the known compounds were performed by comparing their physical and spectral data (IR, UV, MS, and NMR) with literature values. This paper deals with the structural elucidation of compounds 1-4.

The HR-EI-MS of 1 exhibited a molecular ion peak at $m / z$ 380.1476, which is corresponded to the molecular formula $\mathrm{C}_{19} \mathrm{H}_{24} \mathrm{O}_{8}$ and indicated eight degrees of unsaturation. The IR spectrum showed the presence of hydroxy $\left(3,337 \mathrm{~cm}^{-1}\right)$ and phenyl $\left(1,619\right.$ and $\left.1,500 \mathrm{~cm}^{-1}\right)$ functionalities. The UV spectrum displayed the aromatic maximum absorption peak at $283 \mathrm{~nm}$. In the ${ }^{1} \mathrm{H}-\mathrm{NMR}$ and DEPT spectra of $\mathbf{1}$, the signals for five quaternary carbons $\left(\delta_{\mathrm{C}} 110.4,135.0,149.5,151.6,152.8\right)$ and one tertiary carbon $\left(\delta_{\mathrm{C}} 97.7\right)$ attributed a pentasubstituted benzene ring. The five substituents of the benzene ring included 
three methoxy groups $\left(\delta_{\mathrm{H}} 3.75,3.77,4.07 ; \delta_{\mathrm{C}} 55.9,61.1,62.1\right)$, a hydroxyl $\left(\delta_{\mathrm{H}} 8.10\right.$, disappeared on $\mathrm{D}_{2} \mathrm{O}$ exchange), and a methylene $\left(\delta_{\mathrm{H}} 3.67 ; \delta_{\mathrm{C}} 18.3\right)$. From the above evidence, compound 1 was proposed to be a biphenyl derivative linked by a methylene group. The relative positions of those substituents on the benzene rings were determined by the long-range correlations between $\mathrm{H}-5\left(\delta_{\mathrm{H}}\right.$ 6.30) and $\mathrm{C}-1\left(\delta_{\mathrm{C}} 110.4\right), \mathrm{C}-3\left(\delta_{\mathrm{C}} 135.0\right)$, and C-6 $\left(\delta_{\mathrm{C}} 151.6\right) ; \mathrm{H}-7\left(\delta_{\mathrm{H}} 3.67\right)$ and C-1 $\left(\delta_{\mathrm{C}} 110.4\right), \mathrm{C}-2$ $\left(\delta_{\mathrm{C}} 149.5\right)$, and $\mathrm{C}-6\left(\delta_{\mathrm{C}} 151.6\right)$ in the HMBC spectrum of 1. Moreover, 2-OMe, 3-OMe, 4-OMe, and 6$\mathrm{OH}$ also exhibited $\mathrm{HMBC}$ correlations with $\mathrm{C}-2, \mathrm{C}-3, \mathrm{C}-4$, and $\mathrm{C}-6$, respectively. The nOe correlations between $\mathrm{H}-7 / 6-\mathrm{OH}\left(\delta_{\mathrm{H}} 8.10\right)$ and $\mathrm{H}-5 / 4-\mathrm{OMe}\left(\delta_{\mathrm{H}} 3.77\right)$ further assured this proposed structure. Thus, compound 1 was elucidated as bis(6-hydroxy-2,3,4-trimethoxylphen-1-yl)methane.

The IR spectrum of 2 exhibited an absorption band $\left(1735 \mathrm{~cm}^{-1}\right)$ for an ester functionalty. The ${ }^{13} \mathrm{C}-\mathrm{NMR}$ and DEPT spectra indicated the presence of one methyl $\left(\delta_{\mathrm{C}} 13.7\right)$, one methoxy $\left(\delta_{\mathrm{C}} 51.8\right)$, five methylenes $\left[\delta_{\mathrm{C}} 19.0,28.9(\times 2), 30.6,64.6\right]$, and two quaternary carbons $\left(\delta_{\mathrm{C}} 172.3,172.8\right)$. A butoxyl group was elucidated by the COSY correlations between H-1' $\left(\delta_{\mathrm{H}} 4.07\right)$ and $\mathrm{H}-2^{\prime}\left(\delta_{\mathrm{H}} 1.57\right)$; H$2^{\prime}$ and $\mathrm{H}-3^{\prime}\left(\delta_{\mathrm{H}} 1.34\right) ; \mathrm{H}-3^{\prime}$ and $\mathrm{H}-4^{\prime}\left(\delta_{\mathrm{H}} 0.88\right)$. From the above observations, compound 2 was considered as a butanedioate derivative with both methyl and butyl groups. The chemically equivalent signals of two methylene groups $\left(\delta_{\mathrm{H}} 2.60, \mathrm{~s}\right)$ were assigned to be located between $\mathrm{C}-1\left(\delta_{\mathrm{C}} 172.3\right)$ and C-4 $\left(\delta_{\mathrm{C}} 172.8\right)$ according to their HMBC relationship. The proposed structure of 2 was also supported by the molecular ion peak at m/z 188 and the fragmental ion peak at m/z 157 [M-OMe] ${ }^{+}, 129$ [M-

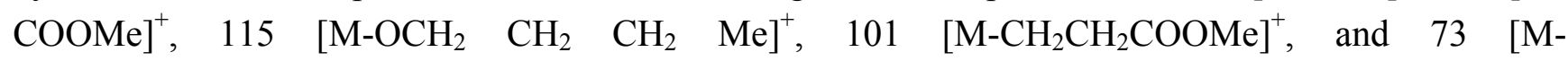
$\left.\mathrm{COCH}_{2} \mathrm{CH}_{2} \mathrm{COOMe}\right]^{+}$in the EI-MS spectrum. Compound 2 was accordingly identified as butylmethyl succinate.

The IR spectrum of 3 showed absorption bands at 3,360 (OH), 1,640 (conjugated ketone), and 1,580 (aromatic) $\mathrm{cm}^{-1}$. The ${ }^{1} \mathrm{H}-\mathrm{NMR}$ and ${ }^{1} \mathrm{H}-{ }^{1} \mathrm{H}$ COSY spectra displayed the signals for a set of aromatic ABX coupling system $\left[\delta_{\mathrm{H}} 6.89(1 \mathrm{H}, \mathrm{d}, J=7.4 \mathrm{~Hz}, \mathrm{H}-7), 7.09(1 \mathrm{H}, \mathrm{d}, J=7.4 \mathrm{~Hz}, \mathrm{H}-5), 7.49\right.$ $(1 \mathrm{H}, \mathrm{t}, J=7.4 \mathrm{~Hz}, \mathrm{H}-6)]$ and a phenolic proton with strong intramolecular hydrogen bond $\left[\delta_{\mathrm{H}} 12.35\right.$ $(1 \mathrm{H}, \mathrm{s}, 8-\mathrm{OH})]$. In addition, the NMR signals for a complex coupling system attributing to a methine $\left[\delta_{\mathrm{H}} 2.30(1 \mathrm{H}, \mathrm{m}, \mathrm{H}-3)\right]$, which was coupled with methyl $\left[\delta_{\mathrm{H}} 1.17\left(3 \mathrm{H}, \mathrm{d}, J=6.6 \mathrm{~Hz}, 3-\mathrm{CH}_{3}\right)\right]$, oxymethine $\left\{\delta_{\mathrm{H}} 4.49(1 \mathrm{H}, \mathrm{dd}, J=6.6,6.9 \mathrm{~Hz}, \mathrm{H}-4)\right.$ coupled with $\left.4-\mathrm{OH}\left[\delta_{\mathrm{H}} 1.92(1 \mathrm{H}, \mathrm{d}, J=6.9 \mathrm{~Hz})\right]\right\}$, and methylene $\left[\delta_{\mathrm{H}} 2.42\left(1 \mathrm{H}, \mathrm{dd}, J=10.1,17.3 \mathrm{~Hz}, \mathrm{H}_{\mathrm{a}}-2\right) ; 2.90\left(1 \mathrm{H}, \mathrm{dd}, J=4.0,17.3 \mathrm{~Hz}, \mathrm{H}_{\mathrm{b}}-2\right)\right]$ was observed. The above features were almost identical to those of the known compound, epiisoshinanolone [15]. Thus, compound 3 was determined as epi-isoshinanolone. It was isolated in pure form for the first time.

Analysis the IR spectrum of 4 suggested that it contains hydroxyl $\left(3,400 \mathrm{~cm}^{-1}\right)$, conjugated ketone $\left(1,668 \mathrm{~cm}^{-1}\right)$, and aromatic $\left(1,620,1,600 \mathrm{~cm}^{-1}\right)$ functionalities. The ${ }^{1} \mathrm{H}-\mathrm{NMR}$ spectrum of 4 revealed the signals for an oxymethine $\left[\delta_{\mathrm{H}} 4.66(1 \mathrm{H}, \mathrm{m}, \mathrm{H}-2)\right]$ coupling to both methyl $\left[\delta_{\mathrm{H}} 1.48(3 \mathrm{H}, \mathrm{d}, J=5.7\right.$ $\left.\left.\mathrm{Hz}, 2-\mathrm{CH}_{3}\right)\right]$ and methylene $\left[\delta_{\mathrm{H}} 2.84(2 \mathrm{H}, \mathrm{m}, \mathrm{H}-3)\right]$, a phenolic proton with strong hydrogen-bonding $\left[\delta_{\mathrm{H}} 11.19(1 \mathrm{H}, \mathrm{s}, 5-\mathrm{OH})\right]$ and a free phenolic proton $\left[\delta_{\mathrm{H}} 5.90(1 \mathrm{H}, \mathrm{s}, 7-\mathrm{OH})\right]$, as well as two metapositioned aromatic protons $\left[\delta_{\mathrm{H}} 6.18(1 \mathrm{H}, \mathrm{s}, \mathrm{H}-8) ; 6.29(1 \mathrm{H}, \mathrm{s}, \mathrm{H}-6)\right]$. The above spectral information was similar to that of 5,7-dihydroxy-2-methylchromanone previously reported in the literature [17]. Thus, compound $\mathbf{4}$ was characterized as 5,7-dihydroxy-2-methylchromanone. Compound 4 was isolated from the natural product for the first time in the present investigation. 
Figure 1. Chemical structures of compounds 1-4.<smiles>COc1cc(O)c([CH]Cc2c(O)cc(OC)c(OC)c2OC)c(OC)c1OC</smiles>

1<smiles>C[C@H]1CC(=O)c2c(O)cccc2[C@H]1O</smiles>

3<smiles>CCCCOC(=O)CCC(=O)OC</smiles>

2

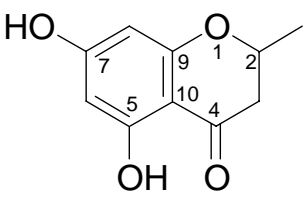

4

Table 1. ${ }^{1} \mathrm{H}$ - and ${ }^{13} \mathrm{C}-\mathrm{NMR}$ spectral data for $\mathbf{1}\left(300\right.$ and $75 \mathrm{MHz}$ in $\left.\mathrm{CDCl}_{3}\right)$.

\begin{tabular}{llllll}
\hline position & $\delta_{\mathrm{C}}$ & $\delta_{\mathrm{H}}$ & position & $\delta_{\mathrm{C}}$ & $\delta_{\mathrm{H}}$ \\
\hline $1,1^{\prime}$ & 110.4 & & 7 & 18.3 & $3.67 \mathrm{~s}$ \\
$2,2^{\prime}$ & 149.5 & & $2,2^{\prime},-\mathrm{OCH}_{3}$ & 62.1 & $4.07 \mathrm{~s}$ \\
$3,3^{\prime}$ & 135.0 & & $3,3^{\prime}-\mathrm{OCH}_{3}$ & 61.1 & $3.75 \mathrm{~s}$ \\
$4,4^{\prime}$ & 152.8 & & $4,4^{\prime}-\mathrm{OCH}_{3}$ & 55.9 & $3.77 \mathrm{~s}$ \\
$5,5^{\prime}$ & 97.7 & $6.30 \mathrm{~s}$ & $6,6^{\prime}-\mathrm{OH}$ & & $8.10 \mathrm{~s}$ \\
$6,6^{\prime}$ & 151.6 & & & & \\
\hline
\end{tabular}

\section{Experimental}

\subsection{General}

Melting points were determined with a Yanagimoto (MP500D) micromelting point apparatus and are uncorrected. IR spectra were recorded on a Perkin-Elmer 781 spectrophotometer. ${ }^{1} \mathrm{H}-$ and ${ }^{13} \mathrm{C}$-NMR spectra were obtained in $\mathrm{CDCl}_{3}$ at a constant temperature controlled and adjusted to around $300 \mathrm{~K}$ on a Bruker AM-300 spectrometer, and the residual proton resonance $\left(\mathrm{CHCl}_{3}\right)$ of $\mathrm{CDCl}_{3}$ was used as internal shift reference. The 2D NMR spectra were recorded on a Bruker DMX-300 spectrometer by using standard pulse sequences. EI-MS, FAB-MS, HR-EI-MS, UV spectra, and specific rotations were recorded on a JEOL JMS-HX 300, a JEOL JMS-HX 110, a JEOL SX-102A, a Hitachi S-3210 spectrometer, and a JASCO DIP-1000 digital polarimeter, respectively. TLC was performed by using Si gel $60 \mathrm{~F}_{254}$ plates (Merck). Column chromatography was performed on silica gel (Merck 9385, 70-230 mesh). HPLC was performed by using a Lichrosorb Si gel 60 (5 $\mu \mathrm{m})$ column $(250 \times 10 \mathrm{~mm})$. 


\subsection{Plant material}

The stems of D. maritima were collected in Lin-Ko, Taiwan, in 1993. The plant material was identified by Muh-Tsuen Gun, formerly a technician of the Department of Botany, National Taiwan University, and a voucher specimen has been deposited at the National Research Institute of Chinese Medicine, Taipei, Taiwan, R.O.C.

\subsection{Extraction and isolation}

The stems of D. maritima $(16 \mathrm{~kg})$ were extracted three times with $\mathrm{EtOH}(160 \mathrm{~L})$ at $60{ }^{\circ} \mathrm{C}$ for $10 \mathrm{~h}$ each time. The EtOH extract was evaporated under reduced pressure, yielding a black residue, which was suspended in $\mathrm{H}_{2} \mathrm{O}(12 \mathrm{~L})$, and then partitioned $(\times 5)$ with $1 \mathrm{~L}$ of $n$-hexane. The aqueous layer was partitioned $(\times 4)$ again with $1 \mathrm{~L}$ of $n-\mathrm{BuOH}$. The combined $n$ - $\mathrm{BuOH}$ extracts $(180 \mathrm{~g})$ was then subjected to column chromatography over silica gel $(120 \times 6 \mathrm{~cm})$ eluted with a setpwise gradient mixture of hexane and EtOAc as eluent. Seven fractions were collected as follows: 1 [3000 mL, hexane], 2 [4000 mL, hexane-EtOAc (9:1)], 3 [4000 mL, hexane-EtOAc (8:2)], 4 [4000 mL, hexane-EtOAc (7:3)], 5 [4000 mL, hexane-EtOAc (5:5)], 6 [3000 mL, hexane-EtOAc (3:7)], and $7(6000 \mathrm{~mL}$, EtOAc). Fraction $1(8.5 \mathrm{~g})$ was further purified through a silica gel column eluted with $n$-hexane/EtOAc (95/5) to yield 16 (6.2 mg). Fraction 3 (27.2 g) was further chromatographed on a silica gel column eluted with $n$-hexane/EtOAc (8/2) and semipreparative HPLC eluted with $\mathrm{CH}_{2} \mathrm{Cl}_{2} / n$ hexane/EtOAc (8/3/1) to obtain $8(5.3 \mathrm{mg}), \mathbf{9}(3.0 \mathrm{mg}), \mathbf{1 0}(3.6 \mathrm{mg}), \mathbf{1 1}(5.1 \mathrm{mg})$, and $15(4.2 \mathrm{mg})$. Fraction $4(38.5 \mathrm{~g})$ was subjected to column chromatography over silica gel eluted with $n$-hexane/EtOAc (7/3) and semipreparative HPLC eluted with $\mathrm{CH}_{2} \mathrm{Cl}_{2} / n$-hexane/EtOAc (3/3/1) to yield 3 (3.8 mg), 5 (3.5 mg), 6 (6.1 mg), 7 (5.0 mg), 12 (12.4 mg), 17 (3.0 mg), 18 (6.3 mg), 19 (4.0 mg), 20 $(10.1 \mathrm{mg}), 21(4.7 \mathrm{mg}), 22(5.1 \mathrm{mg}), 27(4.1 \mathrm{mg})$, and $30(3.0 \mathrm{mg})$. Fraction 5 (32.1 g) was further chromatographed on silica gel eluted with $n$-hexane/EtOAc $(5 / 5)$ and semipreparative HPLC eluted with $\mathrm{CH}_{2} \mathrm{Cl}_{2} / n$-hexane/EtOAc (2/3/1) to yield $1(5.2 \mathrm{mg}), 2(10.5 \mathrm{mg}), 4(3.2 \mathrm{mg}), 13(3.1 \mathrm{mg}), 14$ $(6.2 \mathrm{mg}), 23(3.1 \mathrm{mg}), 24(3.2 \mathrm{mg}), 25(3.0 \mathrm{mg}), 26(3.5 \mathrm{mg}), 28(4.7 \mathrm{mg}), 29(2.8 \mathrm{mg})$, and $31(4.0 \mathrm{mg})$.

\subsection{Spectroscopic data}

Bis(6-hydroxy-2,3,4-trimethoxylphen-1-yl)methane (1): Gum; UV (loge) (MeOH) $\lambda_{\max }$ : 283 (3.4) nm; IR $\nu_{\max } \mathrm{cm}^{-1}: 3337,1619,1500,1208,1082,897 ;{ }^{1} \mathrm{H}-$ and ${ }^{13} \mathrm{C}-\mathrm{NMR}\left(\mathrm{CDCl}_{3}\right)$ : see Table 1; EI-MS $(70$ eV) m/z (rel. int. \%): 380 [M] ${ }^{+}$(38), 211 (23), 197 (39), 184 (100), 169 (42), 57 (25); HR-EI-MS m/z 380.1476 (calcd for $\mathrm{C}_{19} \mathrm{H}_{24} \mathrm{O}_{8}, 380.1471$ ).

Butylmethyl succinate (2): Colorless oil; IR $v_{\max } \mathrm{cm}^{-1}: 1735,1155,1016 ;{ }^{1} \mathrm{H}-\mathrm{NMR}\left(\mathrm{CDCl}_{3}\right): \delta 0.88$ $(3 \mathrm{H}, \mathrm{t}, J=7.6 \mathrm{~Hz}, \mathrm{H}-4$ ') 1.34 (2H, sex, $J=7.6 \mathrm{~Hz}, \mathrm{H}-3$ '), 1.57 (2H, quin, $J=7.6 \mathrm{~Hz}, \mathrm{H}-2$ '), 2.60 (4H, s, H-2, 3), $3.67\left(3 \mathrm{H}, \mathrm{s},-\mathrm{OCH}_{3}\right), 4.07\left(2 \mathrm{H}, \mathrm{t}, J=7.6 \mathrm{~Hz}, \mathrm{H}-1^{\prime}\right) ;{ }^{13} \mathrm{C}-\mathrm{NMR}\left(\mathrm{CDCl}_{3}\right): \delta 13.7\left(\mathrm{C}-4{ }^{\prime}\right), 19.0$ (C-3'), 28.9 (C-2, 3), 30.6 (C-2'), $51.8\left(-\mathrm{OCH}_{3}\right), 64.6$ (C-1'), 172.3 (C-1), 172.8 (C-4); EI-MS (70 eV) m/z (rel. int. \%): $188\left[\mathrm{M}^{+}(1), 157\right.$ (8), 129 (38), 115 (78), 101 (100), 87 (38), 73 (9), 55 (58); HR-EIMS m/z 188.0940 (calcd for $\mathrm{C}_{9} \mathrm{H}_{16} \mathrm{O}_{4}$ ). 
epi-Isoshinanolone (3): Amorphous solid; IR (dry film) $v_{\max } \mathrm{cm}^{-1}$ : 3360, 1640, 1580; ${ }^{1} \mathrm{H}-\mathrm{NMR}$ $\left(\mathrm{CDCl}_{3}\right): \delta 1.17\left(3 \mathrm{H}, \mathrm{d}, J=6.6 \mathrm{~Hz}, 3-\mathrm{CH}_{3}\right), 1.92(1 \mathrm{H}, \mathrm{d}, J=6.9 \mathrm{~Hz}, 4-\mathrm{OH}), 2.30(1 \mathrm{H}, \mathrm{m}, \mathrm{H}-3), 2.42$ $\left(1 \mathrm{H}, \mathrm{dd}, J=10.1,17.3 \mathrm{~Hz}, \mathrm{H}_{\mathrm{a}}-2\right), 2.90\left(1 \mathrm{H}, \mathrm{dd}, J=4.0,17.3 \mathrm{~Hz}, \mathrm{H}_{\mathrm{b}}-2\right), 4.49(1 \mathrm{H}, \mathrm{dd}, J=6.6,6.9 \mathrm{~Hz}$, H-4), 6.89 (1H, d, J=7.4 Hz, H-7), 7.09 (1H, d, J=7.4 Hz, H-5), 7.49 (1H, t, $J=7.4$ Hz, H-6), 12.35 (1H, s, 8-OH); EI-MS (70 eV) m/z [M] 192 (90), 177 (20), 150 (45), 121 (100).

5,7-Dihydroxy-2-methylchromanone (4): Amorphous solid; IR (dry film) $v_{\max } \mathrm{cm}^{-1}: 3400,1668,1620$, 1600; ${ }^{1} \mathrm{H}-\mathrm{NMR}\left(\mathrm{CDCl}_{3}\right)$ : $\delta 1.48\left(3 \mathrm{H}, \mathrm{d}, J=5.7 \mathrm{~Hz}, 2-\mathrm{CH}_{3}\right), 2.84(2 \mathrm{H}, \mathrm{m}, \mathrm{H}-3), 4.66(1 \mathrm{H}, \mathrm{m}, \mathrm{H}-2)$, $5.90(1 \mathrm{H}, \mathrm{s}, 7-\mathrm{OH}), 6.18$ (1H, s, H-8), 6.29 (1H, s, H-6), $11.19(1 \mathrm{H}, \mathrm{s}, 5-\mathrm{OH})$; EI-MS (70 eV) m/z 194 $[\mathrm{M}]^{+}(40), 185$ (100), $149(69)$.

\section{Conclusions}

Thirty-one compounds were isolated from the stems of D. maritima. Among them, bis(6-hydroxy2,3,4-trimethoxylphen-1-yl)methane (1) and butylmethyl succinate (2) are new compounds and epiisoshinanolone (3) was isolated in pure form for the first time. In addition, 5,7-dihydroxy-2methylchromanone (4) was isolated from the natural source for the first time. This investigation of secondary metabolites may contribute to better understanding on the chemical characteristics of $D$. maritima.

\section{Acknowledgements}

This research was supported by the National Science Council, Republic of China and China Medical University (CMU98-CT-01). We thank Shou-Ling Huang and Shu-Yun Sun for the NMR data acquisition and HR-EI-MS measurement in the Instrumentation Center of the College of Science, National Taiwan University. We are grateful to the National Center for High-performance Computing for computer time and facilities.

\section{References and Notes}

1. Higa, M.; Ogihara, K.; Yogi, S. Bioactive naphthoquinone derivatives from Diospyros maritima Blume. Chem. Pharm. Bull. 1998, 46, 1189-1193.

2. Higa, M.; Noha, N.; Yokaryo, H; Ogihara, K.; Yogi, S. Three new naphthoquinone derivatives from Diospyros maritima BLUME. Chem. Pharm. Bull. 2002, 50, 590-593.

3. Kuo, Y.H.; Chang, C.I; Li, S.Y.; Chou, C.J.; Chen, C.F.; Kuo, Y.H.; Lee, K.H. Cytotoxic constituents from the stems of Diospyros maritima. Planta Med. 1997, 63, 363-364.

4. Gu, J.Q.; Graf, T.N.; Lee, D.; Chai, H.B.; Mi, Q.; Kardono, L.B.; Setyowati, F.M.; Ismail, R.; Riswan, S.; Farnsworth, N.R.; Cordell, G.A.; Pezzuto, J.M.; Swanson, S.M.; Kroll, D.J.; Falkinham, J.O., 3rd; Wall, M.E.; Wani, M.C.; Kinghorn, A.D.; Oberlies, N.H. Cytotoxic and antimicrobial constituents of the bark of Diospyros maritima collected in two geographical locations in Indonesia. J. Nat. Prod. 2004, 67, 1156-1161.

5. Kan, W.S. Pharmaceutical Botany; National Research Institute of Chinese Medicine: Taipei, Taiwan, 1997; p. 440. 
6. Tezuka, M.; Takahashi, C.; Kuroyanagi, M.; Satake, M.; Yoshihira, K.; Natori, S. New naphthoquinones from Diospyros. Phytochemistry 1973, 12, 175-183.

7. Kuo, Y.H.; Chang, C.I.; Kuo, Y.H. New naphthoquinones from the stem of Diospyros maritima Blume. J. Chin Chem. Soc. 1996, 43, 511-514.

8. Kuo, Y.H.; Chang, C.I.; Kuo, Y.H.; Huang, S.L. Three new naphthoquinones from the stem of Diospyros maritima Blume. J. Chin. Chem. Soc. 1998, 45, 111-114.

9. Kuo, Y.H.; Chang, C.I.; Kuo, Y.H. Triterpenes from the stem of Diospyros maritima Blume. Phytochemistry 1997, 46, 1135-1137.

10. Kuo, Y.H.; Chang, C.I.; Kuo, Y.H. A novel trisnorlupane, diospyrolide, from Diospyros maritima. Chem. Pharm. Bull. 1997, 45, 1221-1222.

11. Chang, C.I.; Kuo, Y.H. Three new lupane-type triterpenes from Diospyros maritima. Chem. Pharm. Bull. 1998, 46, 1627-1629.

12. Chang, C.I.; Kuo, Y.H. Two new lupane-type triterpenes from Diospyros maritima. J. Nat. Prod. 1999, 62, 309-310.

13. Kuo, Y.H.; Chang, C.I. Six new compounds from the heartwood of Diospyros maritima. Chem. Pharm. Bull. 2000, 48, 1211-1214.

14. Kuo, Y.H.; Huang, S.L.; Chang, C.I. A phenolic and an aliphatic lactone from the Diospyros maritima. Phytochemistry 1998, 49, 2505-2507.

15. Bhattacharyya, J.; De Carvalho, V.R. epi-Isoshinanolone from Plumbago scandens. Phytochemistry 1986, 25, 764-765.

16. Chandler, I.M.; Mclntyre, C.R.; Simpson, T.J. Structural revision and synthesis of $11-\mathrm{d} 253$ and related chromanone fungal metabolites. J. Chem. Soc. Perkin Trans. 1 1992, 2271-2284.

17. Anderson, J.R.; Edwards, R.L.; Whalley, A.J.S. 3-Methyl-3,4-dihydroisocoumarins and related compounds from the ascomycete family Xylariaceae. J. Chem. Soc. Perkin Trans. 1 1983, 2185-2192.

18. Auricchio, S.; Morrocchi S.; Ricca, A. Phenol compounds from isoxazoles, considered as masked $\beta$-polyketones. Tetrahedron Lett. 1974, 15, 2793-2796.

19. Gramatica, P.; Gianotti, M.P.; Speranra, G.; Manitto, P. Synthesis of naturally occurring 2,5dialkylchromones. Part 1: Synthesis of aloesone and aloesol. Heterocycles 1986, 24, 743-750.

20. Lee, C.K.; Chang. M.H. The chemical constituents from the heartwood of Eucalyptus citrodora. J. Chin. Chem. Soc. 2000, 47, 555-560.

21. Ito, J.; Chang, F.R.; Wang, H.K.; Park, Y.K.; Ikegaki, M.; Kilgore, N.; Lee, K.H. Anti-AIDS agents. 48. anti-HIV activity of moronic acid derivatives and the new melliferone-related triterpenoid isolated from Brazilian Propolis. J. Nat. Prod. 2001, 64, 1278-1281.

22. Crestini, C.; D'Auria, M. Singlet oxygen in the photodegradation of lignin models. Tetrahedron, 1997, 53, 7877-7888.

23. Carpinella, M.C.; Giorda, L.M.; Ferrayoli, C.G.; Palacios, S.M. Antifungal effects of different organic extracts from Melia azedarach L. on phytopathogenic fungi and their isolated active components. J. Agric. Food Chem. 2003, 51, 2506-2511.

24. Daubresse, N.; Francesch, C.; Mhamdi, F.; Rolando, C. A mild synthesis of coumaryl, coniferyl, sinapyl aldehydes and alcohols. Synthesis 1994, 4, 369-371. 
25. Otsuka, H.; Takeuchi, M.; Inoshiri, S.; Sato, T.; Yamasaki, K. Phenolic compounds from Coix lachrymal-jobi var. ma-yuen. Phytochemistry 1989, 28, 883-886.

26. Fuchino, H.; Saton, T.; Tanaka, N. Chemical evaluation of Betula species in Japan. I. constituents of Betula ermanii. Chem. Pharm. Bull. 1995, 43, 1937-1942.

27. Saraswathy, A.; Sasikala, E. betulin-28-acetate from Capparis sepiaria L. J. Indian Chem. Soc. 1991, 68, 633-634.

28. Rashid, M.A.; Gray, A.I.; Waterman, P.G.; Armstrong, J.A. Coumarins from Phebalium tuberculosum ssp. megaphyllum and Phebalium filifolium. J. Nat. Prod. 1992, 55, 851-858.

29. Zhong, S.M.; Waterman P.G.; Jeffreys, J.A.D. Naphthoquinones and triterpenes from African Diospyros species. Phytochemistry 1984, 23, 1067-1072.

30. Kuo, Y.H.; Chu, P.H. Studies on the constituents from the bark of Bauhinia purpurea. J. Chin. Chem. Soc. 2002, 49, 269-274.

31. Kundu, A.B.; Barik, B.R.; Mondal, D.N.; Dey, A.K.; Banerji, A. Zizyberanalic acid, a pentacyclic triterpenoid of Zizyphus jujuba. Phytochemistry 1989, 28, 3155-3158.

32. Barba, B.; Diaz J.G.; Herz, W. Cassanes and anthraquinones from Chamaecrista greggii. Phytochemistry 1994, 37, 837-845.

33. Ahman, V.U.; Basha, A.; Rahman, A. Identification and C-13 N.M.R. spectrum of stachydrine from Cadaba fruticosa. Phytochemistry 1975, 14, 292-293.

34. Majumder, P.L; Bagchi, A. Oxidative transformations of triterpenoids of the ursane and oleanane skeleta with hydrogen peroxide. introduction of 11,12-double bond and 13(28)oxide moiety in the ursane system. Tetrahedron 1983, 39, 649-655.

35. Elujoba, A.A; Fell, A.F.; Linley P.A.; Maitland, D.J. Triterpenoid saponins from fruit of Lagenaria breviflora. Phytochemistry 1990, 29, 3281-3285.

36. Tkachev, A.V.; Denisov, A.Y. Oxidative decarboxylation by hydrogen peroxide and a mercury (II) salt: A simple route to nor-derivatives of acetyloleanolic, acetylursolic and dehydroabietic acids. Tetrahedron 1994, 50, 2591-2598.

37. Tkachev, A.V.; Denisov, A.Y.; Gatilov, Y.V.; Bagryanskaya, I.Y.; Shevtsov, S.A.; Rybalova, T.V. Stereochemistry of hydrogen peroxide-acetic acid oxidation of ursolic acid and related compounds. Tetrahedron 1994, 50, 11459-11488.

38. Errington, S.G.; Jefferies, P.R. Triterpenoid sapogenins of Pittosporum phillyraeoides. Phytochemistry 1988, 27, 543-545.

Sample Availability: Samples of the compounds are available from the authors.

(C) 2009 by the authors; licensee Molecular Diversity Preservation International, Basel, Switzerland. This article is an open-access article distributed under the terms and conditions of the Creative Commons Attribution license (http://creativecommons.org/licenses/by/3.0/). 